\title{
Potential consequences of selection to change gestation length on performance of Holstein cows
}

\author{
H. D. Norman, ${ }^{1}$ J. R. Wright, and R. H. Miller \\ Animal Improvement Programs Laboratory, Agricultural Research Service, USDA, Beltsville, MD 20705-2350
}

\begin{abstract}
Genetic evaluations for gestation length (GL) for Holstein service sires were studied to determine their effectiveness in predicting GL in an independent data set. Consequences of selection on GL were also assessed by examining correlated changes in milk and fitness traits. Holstein bulls with $\geq 300$ calvings between 1998 and 2005 were stratified into the following 7 groups using predicted transmitting ability (PTA) for service sire GL: $<-3.00,-3.00$ to $-2.01, \ldots, 1.00$ to 1.99 , and $\geq 2.00 \mathrm{~d}$. An independent set of 261,598 first-parity cows mated later to the same bulls and calving between 2006 and 2009 were segregated by the service sire PTA GL groups (group had 8,317 to 73,324 gestations), and these mates' GL were examined to determine effectiveness of service sire PTA GL. The model included fixed effects for herd-year and service sire group, plus covariates for conception dates to account for time opportunity among mates. Mean GL for mates by service sire group (from lowest to highest PTA GL) were 275.3, 276.5, 277.8, 278.6, 279.5, 280.6, and 281.7 d. Thus, service sire PTA GL was effective in identifying bulls that modified GL. Subsequent yield and fitness traits were also examined for the (independent) mates with the same service sire groups. Intermediate service sire PTA GL was optimal for yield traits and days open; performance for productive life and culling generally became less favorable as service sire PTA GL increased. A second examination was made by replacing service sire PTA GL groups in the model with phenotypic cow GL groups. Relationships between GL and subsequent performance for milk yield and fitness traits were examined using 9 phenotypic cow GL groups: $\leq 271$, $272-273, \ldots, 284-285$, and $\geq 286$ d. Performance generally improved for subsequent lactation yield as cow GL increased; however, intermediate GL was optimal for productive life, calving ease, stillbirth, culling, and days open. Results indicated that neither shortening nor increasing the mean for GL in the Holstein breed
\end{abstract}

Received August 17, 2010.

Accepted October 19, 2010.

${ }^{1}$ Corresponding author: Duane.Norman@ars.usda.gov provided much overall benefit when all traits were considered. The same traits examined in the cows for the correlated effect from various GL were also examined in their offspring to determine whether the GL producing the calf had any influence on these same traits when the offspring reached their own productive period. Little carryover occurred from GL on the dam to the other traits observed on the offspring when examined a generation later.

Key words: gestation length, milk yield, fitness trait, productive life

\section{INTRODUCTION}

Gestation length (GL), the interval from conception to subsequent parturition, was examined recently using data from DHI herds in the United States (Norman et al., 2009). Selected means and standard deviations were reported for breed, parity, parturition code (sex and multiple-birth status), conception year and month, region, cow lactation length, and cow milk yield, providing information needed to accurately predict calving date.

Several studies (e.g., Andersen and Plum, 1965; Hansen et al., 2004; Jamrozik et al., 2005; Norman et al., 2009) found that genetic variation in GL is large enough to change GL through selection. Heritability estimates for GL based on service sire have been higher than those based on cow sire (around 0.40 and 0.10, respectively; Hansen et al., 2004; Jamrozik et al., 2005; Norman et al., 2009). Thus, GL is more a characteristic of the fetus than of the dam (Meyer et al., 2000). King et al. (1985), using embryo transfer studies, showed that breed of the fetus was more important than breed of recipient cow in influencing GL.

Norman et al. (2009) investigated genetic and environmental factors that affect GL and developed service sire and cow-sire genetic evaluations for GL based on heifer and cow gestations separately. They reported PTA for GL of Holstein bulls that ranged from -5.4 to $5.3 \mathrm{~d}$ for service sire GL (8,427 bulls) and -2.8 to $3.1 \mathrm{~d}$ for cow-sire GL (3,964 bulls). Their correlations between Holstein cow- and heifer-based PTA for GL were high for both service sire PTA (0.96 to 0.98) and 
cow-sire PTA (0.75 to 0.91). They also found that Holstein service sire and cow-sire PTA for GL were moderately correlated (0.73 for heifer-based PTA and 0.79 for cow-based PTA).

Although GL can be changed genetically, the desired or preferred direction of such a change is not clear. Selecting shorter or longer GL without knowledge of correlated responses could lead to adverse consequences in other traits. A few studies have found small associations between GL and stillbirth (e.g., Chassagne et al., 1999; Hansen et al., 2004; Jamrozik et al., 2005; Manatrinon et al., 2009). However, GL may have an intermediate optimum for stillbirth; for example, Meyer et al. (2000) reported that stillbirth frequency was lowest in multiparous cows with GL closest to the mean. Small correlations between GL and dystocia have also been reported (e.g., Philipsson, 1976; McGuirk et al., 1999; Meyer et al., 2001; Johanson and Berger, 2003; Hansen et al., 2004; Jamrozik et al., 2005). However, GL may also have a nonlinear relationship with dystocia (Niskanen and Juga, 1998). Decreases in GL directly reduced calving intervals, but Hansen et al. (2004) concluded that calving interval was best reduced by selecting for fewer days open (DO). Hageman et al. (1991) found that GL for cows selected for high milk yield were $1.1 \mathrm{~d}$ longer than those for cows selected for mean milk yield. Norman et al. (2009) reported that GL was $0.6 \mathrm{~d}$ longer for cows with standardized milk yield of $\geq 14,001 \mathrm{~kg}$ compared with that of $\leq 8,000 \mathrm{~kg}$. Although GL has limited direct economic significance, it does have indirect effects through correlations with stillbirth, dystocia, and calf size (Hansen et al., 2004). Coincidental selection for shorter or longer GL may have contributed to indirect responses in correlated traits without the full knowledge of dairy producers. To our knowledge, no studies have examined whether GL has any carryover effects on the offspring.

From an examination of the literature, no single optimum for GL is evident for various traits. López de Maturana et al. (2009) proposed that a GL of $274 \mathrm{~d}$ (3 d shorter than mean) would be best for Holsteins as related to dystocia and stillbirth. Because of nonlinear relationships of GL with dystocia and stillbirth, an intermediate GL may be optimal (e.g., Niskanen and Juga, 1998; McGuirk et al., 1999; Meyer et al., 2000, 2001; Johanson and Berger, 2003; Steinbock et al., 2003; Jamrozik et al., 2005). If mid-range GL is optimum, identifying and avoiding use of bulls that transmit extreme GL would be beneficial.

The objective of this paper was to determine if genetic evaluations of Holstein GL were accurate and repeatable and to assess potential consequences of selection for either shorter or longer GL through examining their effect on milk and fitness traits in subsequent record- ing. The same traits examined in the cow for their correlated effect from various GL were also examined in their offspring to determine whether the GL producing the calf had any carryover influence on these same traits when the offspring reached their own productive period.

\section{MATERIALS AND METHODS}

\section{Data Conditioning}

The PTA GL for Holstein bulls from an earlier study (Norman et al., 2009), each based on 300 calvings between January 1998 and December 2005, were stratified into the following 7 groups according to PTA for service sire GL: $<-3.00,-3.00$ to $-2.01,-2.00$ to -1.01 , $\ldots, 1.00$ to 1.99 , and $\geq 2.00 \mathrm{~d}$. An independent set of 261,598 first-parity cows mated to the same bulls with calvings from January 2006 through November 2009 were segregated by service sire PTA GL group (group size of 8,317 to 73,324 gestations). Analyzed traits (Table 1) included GL; calving ease (CE) score (1 to 5 , where 1 is no difficulty and 5 is extreme difficulty); stillbirth incidence (no $=1$; yes $=2)$; DO; standardized milk, fat, and protein yields and SCS; culling incidence $($ no $=1$; yes $=2)$; and productive life $(\mathbf{P L})$. Stillbirth was coded yes if a calf was born dead or died within 48 $\mathrm{h}$ postpartum. Calving ease and stillbirth coding were supplied using uniform formats of the Animal Improvement Programs Laboratory (2010). Standardized yields were actual observations adjusted for calving age and month, lactation length, milking frequency, and previous DO as defined by the Animal Improvement Programs Laboratory. Culled was coded yes if the cow died or left the herd for a nondairy reason (supplied in Animal Improvement Programs Laboratory format 4) during the lactation subsequent to the GL being examined. Gestations included ranged from 260 to $295 \mathrm{~d}$.

The phenotypic relationship in cows between GL and subsequent performance for milk yield and fitness traits was examined using 9 phenotypic cow GL groups: $\leq 271,272$ to 273,274 to $275, \ldots, 284$ to 285 , and $\geq 286$ d; that is, groups based on GL of cows instead of PTA GL of the service sire of the cows. Group size ranged from 18,318 to 45,064 gestations.

\section{Relationships Within the Same Generation}

Mate GL was examined to determine the effectiveness of service sire PTA GL (Norman et al., 2009) as well as the effect GL had on subsequent phenotypic performance of mates for milk and fitness traits. Correlated responses in those traits were assumed to have occurred in the same manner they would have had 
Table 1. Definition of dependent variables examined for mates, cows, or offspring with respect to differences in service sire PTA gestation length (GL) or cow GL

\begin{tabular}{lll}
\hline Dependent variable & Mates or cows & Offspring \\
\hline GL, d & GL during first lactation & GL during first lactation \\
Calving ease, score & Second-parturition score & First-parturition score \\
Stillbirth, \% & Second-parturition stillbirth code & First-parturition stillbirth code \\
Days open & Days open during second lactation & Days open during first lactation \\
Milk, kg & Second-lactation standardized yield & First-lactation standardized yield \\
Fat, kg & Second-lactation standardized yield & First-lactation standardized yield \\
Protein, kg & Second-lactation standardized yield & First-lactation standardized yield \\
SCS & Second-lactation standardized SCS & First-lactation standardized SCS \\
Culled, \% & Second-lactation termination code & First-lactation termination code \\
Productive life, mo & Time in milking herd before removal by culling or death & Time in milking herd before \\
& & removal by culling or death \\
\hline
\end{tabular}

intentional selection been directed toward either shortening or lengthening GL. Variability in GL would have contributed to differences in the population in spite of the fact that selection transpired largely without producer knowledge because predictions for GL were not available to the dairy industry throughout the entire period. The assumption made is that one should expect similar results through correlated responses if direct selection were practiced to change GL.

Model 1 included fixed effects for herd-year of conception (HY) and service sire PTA GL group, as well as covariates for conception date $(\mathbf{C D})$ and $\mathrm{CD}^{2}$ to provide equitable opportunity for performance among mates (e.g., PL):

$$
\begin{aligned}
\mathrm{y}_{\mathrm{ijkm}}= & \mathrm{HY}_{\mathrm{i}}+\text { service sire PTA GL group }_{\mathrm{j}} \\
& +\mathrm{b}_{1}\left(\mathrm{CD}_{\mathrm{k}}\right)+\mathrm{b}_{2}\left(\mathrm{CD}_{\mathrm{k}}{ }^{2}\right)+\mathrm{e}_{\mathrm{ijkm}},
\end{aligned}
$$

where $\mathrm{y}_{\mathrm{ijkm}}$ is the phenotypic trait in the subsequent lactation of cow $\mathrm{m}$ that resulted from a conception on day $\mathrm{k}$ in herd-year $\mathrm{i}$ from a mating to a service sire with a PTA GL in group $j, b_{1}$ and $b_{2}$ are linear and quadratic regression coefficients, and e is residual.

Likewise, a second model (model 2) was designed to analyze the effectiveness of cow GL groups, and the model equation was the same as for model 1 except that service sire PTA GL group ${ }_{j}$ was replaced with a fixed effect for cow GL group $\left(\mathrm{CG}_{\mathrm{j}}\right)$. Least squares means were calculated for service sire PTA GL groups and cow GL groups from the independent data set using the GLM procedure of SAS.

Two alternative models (model $1 \mathrm{a}$ and model 2a) were defined by replacing the service sire groups (in model 1) or cow GL groups (in model 2) with linear and quadratic regression coefficients for the same terms being replaced. This was done solely to determine whether linear and quadratic responses adequately explained the relationship. For example, model 1a was defined as:

$$
\begin{aligned}
\mathrm{y}_{\mathrm{ikm}} & =\mathrm{HY}_{\mathrm{i}}+\mathrm{b}_{\ell}(\text { service sire PTA GL }) \\
& +\mathrm{b}_{\mathrm{q}}(\text { service sire PTA GL } \\
& +\mathrm{b}_{1}\left(\mathrm{CD}_{\mathrm{k}}\right)+\mathrm{b}_{2}\left(\mathrm{CD}_{\mathrm{k}}{ }^{2}\right)+\mathrm{e}_{\mathrm{ikm}},
\end{aligned}
$$

where $b_{\ell}$ is a linear and $b_{q}$ is a quadratic regression coefficient for modeling the effect of individual performance traits on service sire PTA GL. Model 2a was similar except that cow GL was substituted for service sire PTA GL.

\section{Relationships Across Generations}

A third model (model 3) was constructed to determine whether the GL that produced the calf had any influence on the calf's performance as a mature animal and again was similar to earlier models. Model 3 included both fixed effects for herd-years of daughter and dam conceptions $\left(\mathrm{HY}_{\mathrm{h}}\right.$ and $\left.\mathrm{HY}_{\mathrm{i}}\right)$, dam GL group, and dam age when she conceived as well as covariates for daughter $\mathrm{CD}$ and $\mathrm{CD}^{2}$ to eliminate differences in productive opportunity (e.g., duration of herd tests after animal calved):

$$
\begin{aligned}
\mathrm{y}_{\text {hijklm }} & =\mathrm{HY}_{\mathrm{h}}+\mathrm{HY} \mathrm{Y}_{\mathrm{i}}+\text { dam } \mathrm{GL}_{\mathrm{j}}+\text { dam age }_{1} \\
& +\mathrm{b}_{1}\left(\mathrm{CD}_{\mathrm{k}}\right)+\mathrm{b}_{2}\left(\mathrm{CD}_{\mathrm{k}}{ }^{2}\right)+\mathrm{e}_{\mathrm{hijklm}},
\end{aligned}
$$

where $y_{\text {hijklm }}$ is the first observation on the daughter that resulted from a conception on day $\mathrm{k}$ in herd-year $\mathrm{h}$ from the dam in GL group $\mathrm{j}$ and in age group 1 that calved in herd-year $i, b_{1}$ and $b_{2}$ are regression coefficients on $C D$, and $\mathrm{e}$ is residual. An alternative model (model 3a) was defined by substituting linear and quadratic regression coefficients for the dam GL simply to determine the nature and statistical significance of the response.

\section{RESULTS AND DISCUSSION}

Least squares means by service sire PTA GL group and the number of mates' subsequent gestations associ- 
Table 2. Least squares means of phenotypic performance by trait and service sire PTA gestation length (GL) group

\begin{tabular}{|c|c|c|c|c|c|c|c|}
\hline Trait $^{1}$ & \multicolumn{7}{|c|}{ Service sire PTA GL group } \\
\hline Calving ease, score & 1.30 & 1.32 & 1.34 & 1.36 & 1.36 & 1.38 & 1.42 \\
\hline Stillbirth, \% & 3.3 & 4.3 & 4.2 & 4.5 & 4.7 & 4.4 & 5.7 \\
\hline Days open & 142.8 & 142.2 & 140.4 & 142.5 & 141.2 & 143.5 & 144.7 \\
\hline Protein, kg & 350.5 & 350.6 & 352.4 & 353.2 & 353.2 & 353.3 & 352.5 \\
\hline SCS & 2.70 & 2.69 & 2.69 & 2.68 & 2.68 & 2.69 & 2.70 \\
\hline Culled, \% & 19.1 & 19.4 & 19.4 & 19.2 & 19.5 & 20.4 & 20.4 \\
\hline Productive life, mo & 34.8 & 34.9 & 34.8 & 34.9 & 34.8 & 34.5 & 34.5 \\
\hline Records, no. & 8,317 & 26,305 & 59,989 & 73,324 & 46,051 & 37,559 & 10,053 \\
\hline
\end{tabular}

${ }^{1}$ Recorded from mate's second lactation except productive life; all traits were significant $(P<0.001)$ across service sire PTA GL groups except for GL $(P<0.0001)$, stillbirth and days open $(P<0.01)$, and SCS (NS).

ated with each service sire PTA GL group are shown in Table 2 . The number of mates within each group ranged from 8,317 to 73,324 . Mean GL for mates increased without exception from $275.3 \mathrm{~d}$ for lowest service sire PTA group to $281.7 \mathrm{~d}$ for highest PTA group. Model 1a (with service sire PTA GL as a continuous variable) produced a linear regression coefficient of $1.01 \pm 0.01$ with a correlation of 0.50 . Thus, PTA for GL was extremely effective in identifying bulls that would modify GL and (as a direct consequence) calving interval. Those results support findings by Andersen and Plum (1965), Hansen et al. (2004), and Jamrozik et al. (2005), who indicated that GL could be modified through selection.

Service sire PTA GL affected all other traits of mates except SCS (nonsignificant). Significance was at $P<$ 0.01 for stillbirth and DO and $P<0.001$ or $P<0.0001$ for other traits. Model 1a confirmed a curvilinear relationship between service sire PTA GL and performance in subsequent lactation for milk, fat, and protein yields and DO; intermediate service sire PTA GL was optimum for each $(P<0.01)$. For culling and PL, performance generally became less favorable as service sire PTA GL increased $(P<0.05)$.

Table 3 shows the number of cows within each GL group: 18,318 to 45,064 . Cow GL group effect had a significant $(P<0.001)$ effect on all traits except SCS. Statistical tests (model 2a) showed that all traits except SCS had linear and quadratic coefficients that were significant $(P<0.001)$ when regressions on cow GL replaced fixed or categorical cow group in the model. Intermediate GL was optimal for CE, stillbirth, culling, and PL. The optimum for CE score covered a broad range (274 to 279 d of GL), whereas the lowest stillbirth was achieved from 280 to 281 d of GL. Philipsson (1976) and Niskanen and Juga (1998) found that calving difficulties were more common if a GL was abnormal (i.e., too short or too long). After very short gestations, calves are often small and weak, and if the GL are too long, calves can grow too big, which causes difficulty in calving. Meyer et al. (2000) reported that

Table 3. Least squares means of phenotypic performance by trait and cow gestation length (GL) group

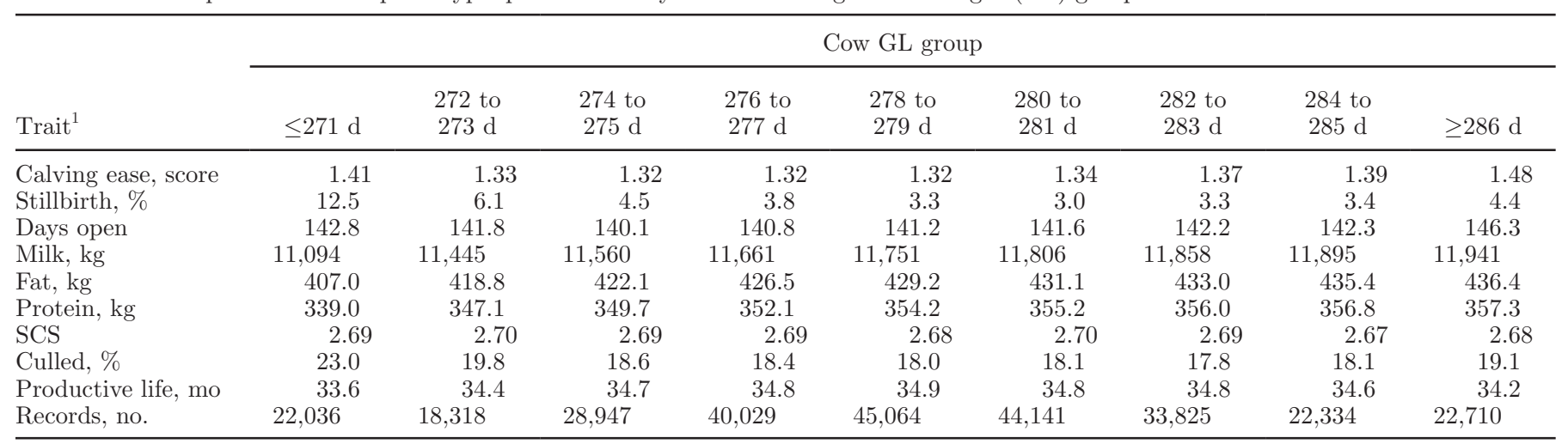

${ }^{1}$ Recorded from cow's second lactation except productive life; all traits were significant $(P<0.001)$ across cow GL groups except for SCS (NS). 
Table 4. Least squares means of daughter phenotypic performance by trait and dam gestation length (GL) group

\begin{tabular}{|c|c|c|c|c|c|c|c|c|c|}
\hline Trait $^{1}$ & \multicolumn{9}{|c|}{ Dam GL group } \\
\hline Calving ease, score & 1.40 & 1.40 & 1.40 & 1.41 & 1.42 & 1.42 & 1.44 & 1.44 & 1.45 \\
\hline Stillbirth, \% & 5.1 & 4.9 & 5.2 & 5.2 & 5.1 & 5.1 & 5.2 & 5.7 & 5.6 \\
\hline Days open & 133.0 & 135.1 & 137.2 & 139.0 & 140.3 & 141.9 & 143.5 & 144.0 & 144.6 \\
\hline SCS & 2.77 & 2.77 & 2.75 & 2.75 & 2.74 & 2.73 & 2.72 & 2.72 & 2.71 \\
\hline Culled, \% & 10.1 & 10.0 & 9.8 & 9.9 & 10.1 & 10.2 & 10.1 & 10.4 & 10.4 \\
\hline Productive life, mo & 33.6 & 33.8 & 33.8 & 33.8 & 33.8 & 33.7 & 33.6 & 33.5 & 33.3 \\
\hline Records, no. & 58,897 & 61,332 & 106,309 & 156,221 & 192,496 & 192,251 & 141,704 & 88,385 & 86,774 \\
\hline
\end{tabular}

${ }^{1}$ Recorded from daughter's first lactation except productive life; all traits were significant $(P<0.0001)$ across dam GL groups except for stillbirth $(P<0.01)$.

stillbirth was lowest in multiparous cows when GL was close to the mean. Intermediate GL had the shortest DO; the lowest was for the 274 to 275 d GL group. Not surprisingly, the lowest cull rate and longest PL were both in intermediate GL groups (278 to 283 d). Performance generally improved for subsequent lactation milk yields as GL increased. For example, the mean of standardized mature-equivalent milk of the following lactation was 11,094 $\mathrm{kg}$ when GL was $\leq 271 \mathrm{~d}$ and was $11,941 \mathrm{~kg}$ when GL was $\geq 286 \mathrm{~d}$. Likewise, fat increased from 407 to $436 \mathrm{~kg}$ and protein from 339 to $357 \mathrm{~kg}$ as cow GL increased from $\leq 271$ to $\geq 286 \mathrm{~d}$. Perhaps longer GL gives more time for udder tissue to be readied for subsequent lactation at calving. In addition, longer GL probably resulted in a corresponding increase in days dry, because the cow typically would not calve as soon as expected.

Table 4 illustrates whether the GL producing the calf had any carryover influence on the traits when the offspring reached their own productive period. The number of dams with each GL group ranged from 58,897 to 192,496 . Even though all traits were statistically significant $(P<0.001)$, aided by the large number of gestations, only 2 traits showed notable differences in the daughter performance: GL and DO. One might expect a moderate relationship between GL across generations considering the heritability for GL reported earlier (0.12; Norman et al., 2009). A short dam GL from the parturition producing the daughter was associated with fewer DO in the first lactation of the daughter. That regression was higher than expected at $0.64 \pm 0.01$ considering that these were phenotypic recordings and that there is halving across generations.

\section{CONCLUSIONS}

This study adds strong evidence that choice of service sires can either increase or decrease GL of cows to which they are mated. Thus, herd managers could use PTA of GL to aid in managing calving schedules or to help in predicting calving date. Relationships between GL and subsequent performance for 3 milk yield traits and 6 fitness traits were real but generally small. It appears that because GL does affect other traits, it has economic value and could be incorporated into a genetic-economic index such as net merit. If warranted, it appears one should not select to increase or decrease the trait, but to discriminate against the extremes. Little evidence was found to suggest that either shortening or increasing GL would provide much overall advantage in the Holstein breed. Virtually no carryover influence occurred from GL on the dam to the other traits observed on the offspring when examined a generation later.

\section{ACKNOWLEDGMENTS}

AgriTech Analytics (Visalia, CA), AgSource Cooperative Services (Verona, WI), Dairy Records Management Systems (Raleigh, NC, and Ames, IA), and DHI Computing Services (Provo, UT) provided pedigree data for grade cows and lactation yields, SCS, DO, and culling data. The Holstein Association USA (Brattleboro, VT), and Red and White Dairy Cattle Association (Crystal Springs, PA) provided pedigree data for registered cows. The National Association of Animal Breeders (Columbia, MO) provided $\mathrm{CE}$ and stillbirth records. Appreciation is extended to G. E. Seidel Jr. (Colorado State University, Fort Collins) for suggestions. 


\section{REFERENCES}

Andersen, H., and M. Plum. 1965. Gestation length and birth weight in cattle and buffaloes: A review. J. Dairy Sci. 48:1224-1235.

Animal Improvement Programs Laboratory. 2010. Data exchange. Accessed October 15, 2010. http://aipl.arsusda.gov/formats/formats. html.

Chassagne, M., J. Barnouin, and J. P. Chacornac. 1999. Risk factors for stillbirth in Holstein herds under field conditions in France: A prospective survey. Theriogenology 51:1477-1488.

Hageman, W. H. II, G. E. Shook, and W. J. Tyler. 1991. Reproductive performance in genetic lines selected for high or average milk yield. J. Dairy Sci. 74:4366-4376.

Hansen, M., M. S. Lund, J. Pedersen, and L. G. Christensen. 2004. Gestation length in Danish Holsteins has weak genetic associations with stillbirth, calving difficulty, and calf size. Livest. Prod. Sci. 91:23-33.

Jamrozik, J., J. Fatehi, G. J. Kistemaker, and L. R. Schaeffer. 2005. Estimates of genetic parameters for Canadian Holstein female reproduction traits. J. Dairy Sci. 88:2199-2208.

Johanson, J. M., and P. J. Berger. 2003. Birth weight as a predictor of calving ease and perinatal mortality in Holstein cattle. J. Dairy Sci. 86:3745-3755.

King, K. K., G. E. Seidel Jr., and R. P. Elsden. 1985. Bovine embryo transfer pregnancies. II. Lengths of gestation. J. Anim. Sci. 61:758-762.

López de Maturana, E. L., X.-L. Wu, D. Gianola, K. A. Weigel, and G. J. M. Rosa. 2009. Exploring biological relationships between calv- ing traits in primiparous cattle with a Bayesian recursive model. Genetics 181:277-287.

Manatrinon, S., B. Furst-Waltl, and R. Baumung. 2009. Genetic parameters for calving ease, gestation length and stillbirth in three endangered Austrian Blond cattle breeds. Arch. Tierzucht. $52: 553-560$.

McGuirk, B. J., I. Going, and A. R. Gilmour. 1999. The genetic evaluation of U.K. Holstein Friesian sires for calving ease and related traits. Anim. Sci. 68:413-422.

Meyer, C. L., P. J. Berger, and K. J. Koehler. 2000. Interactions among factors affecting stillbirths in Holstein cattle in the United States. J. Dairy Sci. 83:2657-2663.

Meyer, C. L., P. J. Berger, J. R. Thompson, and C. E. Sattler. 2001 Phenotypic trends in incidence of stillbirth for Holsteins in the United States. J. Dairy Sci. 84:515-523.

Niskanen, S., and J. Juga. 1998. Calving difficulties and calf mortality in Finnish dairy cattle population. Interbull Bull. 18:17-20.

Norman, H. D., J. R. Wright, M. T. Kuhn, S. M. Hubbard, J. B. Cole, and P. M. VanRaden. 2009. Genetic and environmental factors that affect gestation length in dairy cattle. J. Dairy Sci. 92:2259-2269

Philipsson, J. 1976. Studies on calving difficulty, stillbirth and associated factors in Swedish dairy cattle breeds. V. Effects of calving performance and stillbirth in Swedish Friesian heifers on productivity in the subsequent lactation. Acta Agric. Scand. 26:230-234.

Steinbock, L., A. Nasholm, B. Berglund, K. Johansson, and J. Philipsson. 2003. Genetic studies on stillbirth and calving difficulty in Sweden. J. Dairy Sci. 86:2228-2235. 